Southern Illinois University Carbondale

OpenSIUC

Articles

Morris Library

2007

\title{
How do Psychology Researchers Find Studies to Include in Meta-analyses?
}

Julie Arendt

Southern Illinois University Carbondale, jaarendt@vcu.edu

Follow this and additional works at: http://opensiuc.lib.siu.edu/morris_articles

Part of the Library and Information Science Commons

Copyright 2007 Haworth Press. Published in Behavioral and Social Sciences Librarian, 26(1), 1-23.

Article available from The Haworth Document Delivery Service: 1-800-HAWORTH. E-mail address: docdeliery@haworthpress.com. URL:http://www.HaworthPress.com.

\section{Recommended Citation}

Arendt, J. (2007). How do psychology researchers find studies to include in meta-analyses? Behavioral and Social Sciences Librarian, 26(1), 1-23. doi: 10.1300/J103v26n01_01

This Article is brought to you for free and open access by the Morris Library at OpenSIUC. It has been accepted for inclusion in Articles by an authorized administrator of OpenSIUC. For more information, please contact opensiuc@lib.siu.edu. 
Article available from The Haworth Document Delivery Service: 1-800-HAWORTH. E-mail address: docdeliery@haworthpress.com. URL:〈http://www.HaworthPress.com>.

\title{
How do psychology researchers find studies to include in
}

\author{
meta-analyses?
}

\section{Julie Arendt}

\begin{abstract}
Meta-analysis is a technique used in a variety of disciplines to combine and summarize the findings of previous research. One step in the production of a meta-analysis is a thorough literature search for relevant studies. A variety of methods can be used to increase the number of studies that are found. This study examines the extent to which some of these steps were taken in meta-analyses published in American Psychological Association in journals in 2004. Some techniques were applied in almost all of the meta-analyses, and other techniques were applied in few of the meta-analyses. Implications of these results for librarians are discussed.
\end{abstract}

KEYWORDS. meta-analysis, literature searching, recall, psychology, indexing and abstracting

Introductory Footnote: Julie Arendt is Reference Librarian - Sciences / Assistant Professor, Library Affairs, Southern Illinois University Carbondale, Mail Code 6632, 605 Agriculture Drive, Carbondale, IL 62901 (E-mail: jarendt@lib.siu.edu). 


\title{
How do psychology researchers find studies to include in meta-analyses?
}

\begin{abstract}
Meta-analysis is a technique used in a variety of disciplines to combine and summarize the findings of previous research. One step in the production of a meta-analysis is a thorough literature search for relevant studies. A variety of methods can be used to increase the number of studies that are found. This study examines the extent to which some of these steps were taken in meta-analyses published in American Psychological Association in journals in 2004. Some techniques were applied in almost all of the meta-analyses, and other techniques were applied in few of the meta-analyses. Implications of these results for librarians are discussed.
\end{abstract}




\section{Introduction}

What has research discovered so far? What still is not well understood? Review articles often consider these questions. Systematic reviews use a systematic approach to synthesize the literature on a topic. Unlike a traditional literature review, in which the authors discuss the reports they personally consider the most important, systematic reviews involve a thorough literature search. Reports are chosen for inclusion in a systematic review based on pre-defined criteria rather than on the authors' opinions. It has been argued (e.g. Bent, Shojania, and Saint 2004) that systematic reviews present less biased coverage of a subject than traditional reviews. Systematic reviews that use statistical techniques to combine results across studies are referred to as meta-analyses. Meta-analyses can be found in medical, business, and psychological research.

The basic process of a meta-analysis, as described in Schell and Rathe (1992), has six steps. They are 1) question definition, 2) definition of inclusion parameters including qualitative parameters, 3) collection of data and bibliography, 4) coding of data and statistical analysis, 5) summary of findings and 6) clinical application.

Decisions made at each phase of this process can influence the results of a meta-analysis. Seemingly minor decisions, such limiting the meta-analysis to English language publications, can matter (Egger et al. 1997; Grégoire, Derderian and Le Lorier 1995). The focus of this report is on the decisions made in the collection of data and bibliography. This step is particularly relevant to librarians because a major component of this step is the literature search process.

It is generally believed that the literature search for a meta-analysis should be through. If the literature search is incomplete, important, relevant studies that otherwise would have been included in the meta-analysis may be missed. If missed studies differ in their results from 
studies that are included, the conclusion of the meta-analyses could be erroneous. Erroneous results in a meta-analysis defeat its purpose of correctly synthesize and clarify the available knowledge on a topic. Occasionally meta-analyses are challenged with the claim that the outcome would have been different had other studies had been included (e.g. Stewart and Roth 2001, challenged by Miner and Raju 2004, countered by Stewart and Roth 2004).

There is a growing body of published research about ways to find relevant studies for inclusion in systematic reviews and meta-analyses. Although the research on literature searches for systematic reviews and meta-analyses is not definitive, it is suggestive of methods that can be used to find a large number of studies. Although many of these methods are long-established in library and information science (e.g. Bates 1989), it is useful examine to them in the context of systematic reviews and meta-analyses.

\section{Searching for Unpublished Studies}

One concern in meta-analyses is publication bias, that findings with no statistically significant effect are less likely to get published than findings of an effect. Although there are non-search methods of dealing with publication bias (e.g. Begg and Berlin 1988; Bennett et al. 2004), it has been suggested that meta-analyses should include unpublished reports and reports from small circulation publications. McAuley et al. (2000) examined thirty-three meta-analytic reports in medicine and found that exclusion of grey literature (abstracts, unpublished studies, conference proceedings or programs, graduate theses, book chapters, company reports and applications) would result in an overestimate of intervention effects by an average of $15 \%$. McLeod and Weisz (2004) compared dissertations to published studies on child psychotherapy 
and found that the effect sizes in the dissertations were smaller than those in the published reports and that the dissertations were at least as methodologically strong as the published reports. Unpublished and small distribution studies can be found in dissertation databases, by contacting authors or research groups and by searching conference proceedings and programs.

\section{Searching Multiple Databases}

The indexing and abstracting databases used to find studies also can make a difference in meta-analyses. Sampson et al. (2003) examined meta-analyses that included both studies indexed in the European medical database Embase and studies indexed in the American medical database Medline. The studies indexed only in Embase had significantly smaller estimates of effect sizes than the non-Embase studies, but because the number of studies found only in Embase was small, they only influenced the pooled estimate of the intervention effect by an average of 6\%. Sampson et al. (2003) concluded that random controlled trials indexed in Medline could not be assumed to be like those indexed in databases other than Medline and that meta-analysts should search as many sources as their resources permitted.

Other research supports this conclusion. In their systematic review on rehabilitation for people with mental illness, Brettle and Long (2001) used multiple methods to find ninety-six studies. Almost all of these studies were found through database searches, but no one database was sufficient to locate them all. Forty-two percent of the studies included in the review were found in just one of the databases searched. PsycLIT, which uncovered the highest number of relevant studies, located just $44 \%$ of the studies that they used. Another study (Hood and Wilson 
2001) indicated that searching several databases was necessary to find $80 \%$ of the articles on a topic.

\section{Controlled Vocabulary and Free-Text Searching}

There are many ways to construct a database search (Hawkins and Wagers 1982). One part of this construction process is to decide what terms to enter in the search box. Many database systems include both free-text and controlled vocabulary features.

In a free-text search, the searcher enters the search terms that he or she can think of, and the system queries selected fields of the database for records containing those terms. If the words that the searcher enters are present any of in those fields, the records are retrieved. If they are not present, the records are not retrieved. Many database search interfaces have truncation and wildcard systems, so a searcher only has to type "friend"” to search for friend, friendly, friends, friendship, etc., and some systems perform this function automatically. Such a system does not assist the searcher in thinking of the synonyms, such as pal, acquaintance, buddy, etc, to include in the search. It is up to the searcher to think of all the possible terms that different authors would have used for a particular idea.

Controlled vocabularies attempt to resolve this difficulty. In a controlled vocabulary search, the searcher consults a subject list or a thesaurus of controlled terms that have been specified by the database creator and enters those terms in the search box. The controlled vocabulary designates a particular term for a concept. A database producer adds the relevant terms from the controlled vocabulary into the database records. That way, even if the original 
document does not contain the controlled term, a searcher still is able to find the document by entering the appropriate term from the controlled vocabulary.

Controlled vocabularies are not without problems. The controlled vocabulary itself may contain terms that are near synonyms. Someone searching in PsycINFO for information on aggression in children would find that "aggressive behavior" is listed in the relevant controlled vocabulary, Thesaurus of Psychological Index Terms, but "bullying," "school violence" and "conduct disorder" also are listed there. Instead of facing the problem of thinking of all of the appropriate search terms, the searcher faces the problem of finding all of the relevant terms in the controlled vocabulary. Even if the searcher enters all the relevant terms from the controlled vocabulary, it still is possible that a relevant database record will not contain any of those terms. If the indexer did not consider the document to be about that topic, relevant terms from the controlled vocabulary would not be added to the record. In addition, different databases use different controlled vocabularies, so a controlled vocabulary search of multiple databases would entail looking for the appropriate terms in multiple controlled vocabularies. Finally, sometimes the controlled vocabulary does not have any terms for a particular concept, especially if the topic is a new area of research (Walker and Mulholland, 1992).

Nearly twenty years ago, it was concluded that using a combination of terms found in a controlled vocabulary and free-text terms was necessary for a comprehensive, high-recall search (Tenopir 1987; Bates 1988). van der Weijden et al. (1997) reiterated this point within the context of searching in Medline for systematic reviews. They found that some relevant studies uncovered by using Medical Subject Headings (MeSH) would not have been uncovered with free-text searching, and some uncovered by free-text searching would not have been found using 
MeSH. They concluded, "In a search for diagnostic studies to perform a systematic review, MeSH terms should be combined with freetext terms to gain high sensitivity," (p. 208).

\section{Manual Searching}

It is difficult to find all the published literature on a topic solely by searching indexing and abstracting databases. These databases index selected publications, not all publications in an area. For publications that are indexed, there can be a time lag between publication and appearance in the database. Another problem is that it is difficult to generate a search statement that will retrieve everything. In fifteen searches to identify trials for systematic reviews, Dickersin, Scherer and Lefebvre (1994) carefully constructed search strategies in Medline, and on average, they found only $77 \%$ of the known trials that were indexed there. Because Medline did not index everything, on average, their Medline searches revealed just 51\% of the known trials.

Instead of relying exclusively on databases, studies can be found through manual searches. One manual search technique is to look at the contents of journals that are known to publish articles on a particular topic. Another technique is to use the references listed in review articles or in studies already selected for the meta-analysis to find other studies on the topic. Avenell, Handoll, and Grant (2001), in their search for randomized controlled trials for use in a systematic review, for example, found one study out of fifteen exclusively by manually searching relevant journals and the citations of other randomized controlled trials.

\section{Documenting the Search}


Although there are many ways that the authors of a meta-analysis can increase the number of studies they include in the meta-analysis, these techniques are not universally used. In some cases, an author may deliberately ignore one of the suggestions, such as someone who excludes results not published in peer-reviewed sources out of concern over the quality of the data. Resource limitations also can make it difficult to implement all of the techniques. For example, locating and obtaining unpublished studies can be difficult and time consuming. Simply expanding a database search has costs because there generally is a tradeoff between recall and precision (Lancaster 1972; Bates 1984; Savoy 2005). To find additional relevant documents, additional irrelevant documents also must be examined.

Given the variability among search techniques used, the QUOROM Group (Moher et al. 1999) has promulgated recommendations for the reporting of meta-analyses of randomized controlled trials in medicine. Among those recommendations are that the report include a complete description of the search method, including, "The information sources, in detail (e.g., databases, registers, personal files, expert informants, agencies, manual searching), and any restrictions (years considered, publication status, language of publication),” (p.1897). A complete description allows the reader to assess the thoroughness of the search and makes it easier for others to reproduce the methods applied by the authors. Thus far, the practice of including a complete search strategy is far from universal. In their study of medical metaanalyses, Patrick et al. (2004) found that $29 \%$ of the meta-analyses did not report the search strategy in sufficient detail for the search to be reproducible.

The research on how to find literature for meta-analyses and on documenting the search process often has been published in medical journals and in library and information science 
journals. It is unclear if researchers who conduct meta-analyses in other fields have applied the methods suggested by this literature. To examine the extent to which these suggestions have been implemented in psychology, I used the descriptions provided in the "Method" sections of psychological meta-analyses to explore the search process that the psychology researchers use. In particular, I examined their methods to determine the extent to which they searched for unpublished and small circulation studies, searched multiple databases, used controlled vocabulary and free-text database search methods, and documented the search.

\section{Methods}

Meta-analyses published in American Psychological Association journals in 2004 were examined. These journals were selected because they generally are well-respected within the field of psychology and because they cover a broad range of psychological topics. These journals also were chosen because I wanted to focus on articles in psychology written from a psychological, rather than a medical perspective. A limitation to this approach is that the results may not generalize to meta-analyses published in other journals or in other years, and results may not generalize to systematic reviews that do not apply meta-analytic statistical techniques.

To locate these meta-analyses, I searched in PsycINFO (1806 to September Week Four 2005) for articles with the publisher URL http://www.apa.org. Results were then limited to journals, year 2004, and to methodology Meta Analysis. This produced a list of forty-one articles. Of these articles, one (van Dick et al. 2004) was excluded because it used meta-analytic statistical techniques to summarize data collected within that study rather than using previously published data. Two other articles were excluded because they were not conventional meta- 
analyses. One article (Rotello, Macmillan and Reeder 2004) developed a new model and applied that model to existing data. The other article (Kulic, Horn and Dagley 2004) provided a descriptive summary of the literature without applying meta-analytic statistical techniques. Although both of these articles involved a thorough literature search, I considered them different enough from the conventional meta-analysis to exclude. The remaining thirty-eight articles were used for my investigation.

I examined the literature search methods described in the "Method" section of each article as well as any appendices and tables of search descriptions. This examination was limited to the process described for locating candidate studies for potential inclusion in the meta-analysis and did not extend to the description of the filtering process used by the authors to select which of these candidates to include in the meta-analysis. These descriptions were coded for the search methods used to find studies, the indexing and abstracting databases used, the methods used to search the databases, and the completeness of the description.

For articles that provided a complete list of search terms and databases, I examined the database search strategy more carefully. Search terms listed in were compared to terms provided by the controlled vocabularies of databases the authors searched. This comparison was done for four controlled vocabularies: Thesaurus of Psychological Index Terms for searches in PsycINFO, PsycLIT, Psychological Abstracts or Psychological Literature; ERIC Thesaurus for searches in Education Resources Information Center (ERIC), Medical Subject Headings (MeSH) for searches in Medline or PubMed, and the CINAHL Subject Heading List for searches in the Cumulative Index to Nursing and Allied Health Literature (CINAHL). In all cases, the electronic versions of the controlled vocabularies that were provided within the databases were used. To find psychological index terms, the OVID search interface with PsycINFO was used. 
The EBSCOhost interface was used to find controlled vocabulary terms in ERIC, Medline and CINAHL. Both of these search interfaces provided relevancy-ranked mappings to the controlled vocabularies as well as the broader term, narrower term, related term and scope note information often found in the print thesaurus. To make each comparison, the system was set to map the term entered to terms in the thesaurus or subject heading list. Each search term provided by the authors was entered. If the mapping generated a term that was not included in an author's search, this term was noted. Additional terms in the controlled vocabulary, including broader, narrower and related terms, which the authors did not use but that appeared relevant to the search topic also were noted. Unless the author indicated that they had used truncation or wildcard symbols, if the term provided by the controlled vocabulary was a variant of the word used by the author (e.g. emotions in the controlled vocabulary and emotion in the author's search), this was noted as an excluded term. If the term provided by the controlled vocabulary was a multi-word phrase, and the author had included part of that phrase in their search (e.g. chronic illness in the controlled vocabulary and illness in the author's search), this was not considered an excluded term.

\section{Findings}

\section{Overall Search Methods}

Search descriptions from thirty-eight meta-analyses in psychology journals were examined. These meta-analyses varied in the amount of detail they provided to describe the searches. One article (Gregory et al. 2004) provided almost no description. Instead, the authors 
wrote that they used “...standard procedures for journal literature search” (p. 276) and offered to provide complete details on request. The remaining meta-analyses included some sort of description of the database searching, manual searching, and other search methods used to find studies.

The authors of the meta-analyses used a variety of methods to find studies, as shown in Table 1. Database searching was mentioned in nearly all, thirty-six $(95 \%)$ of the articles. Manual searching methods also were mentioned in thirty-six (95\%) of the meta-analyses. It was less common for the meta-analyses to include a search for unpublished or small circulation studies; fifteen (39\%) of the meta-analyses included a search for unpublished data. Fourteen (37\%) of the meta-analyses included all three: searching for unpublished studies, searching multiple databases, and some form of manual searching.

<Table 1 here>

Some of the meta-analyses used other database search methods to find studies. In their database searches, author searches and citation searches, two methods mentioned by Bates (1989), were employed in some meta-analyses. Three meta-analyses used database searches on author names to find reports by researchers in the topic area. One of these searched for the names of authors from relevant articles used in the meta-analysis; one selected twelve specific authors to search, and one searched on the name of one prominent researcher in the field. Two of the meta-analyses used a citation database to find newer works that cited other works. One of these used the citation database to find studies that cited the studies that had been selected for the meta-analysis, and the other used it to find studies that had cited specific tests that were relevant 
to its topic. Although seven other meta-analyses used the citation databases Web of Science or Social Sciences Citation Index, their search descriptions generally indicated that the databases were used for keyword searching rather than for citation searching.

\section{Searching for Unpublished Studies}

To the extent that the indexing and abstracting databases used by the researchers included conference proceedings and dissertations, it could be argued that all of database searches included some search of unpublished or small circulation material. Less than half, fifteen (39\%), of the meta-analyses specifically sought out unpublished or small circulation studies.

Eleven (29\%) of the meta-analyses mentioned searching for dissertations, making it most common search technique for unpublished material. Ten (26\%) of the meta-analyses used a search of a dissertation abstracting database. One of the meta-analyses obtained dissertations from the authors' personal files and did not indicate that a dissertation abstracting database was used.

Other methods also were used to find unpublished and small circulation studies. Ten (26\%) of meta-analyses mentioned contacts with individual researchers, listservs, or organizations to find unpublished studies. Six contacted researchers individually; four sent messages to relevant listservs, and two contacted organizations. Another method to find unpublished studies was the use of conference proceedings or programs. Four (11\%) of the meta-analyses mentioned use of this method.

\section{Searching Multiple Databases}


Almost all, thirty-six (95\%) of the meta-analyses included a search of an indexing and abstracting database to find relevant studies. Of the other two meta-analyses, one relied solely on manual searching, and the other did not provide a description of the search methods. Most of the meta-analyses, thirty (79\%), named more than one database that was searched.

\section{Controlled Vocabulary and Free-Text Searching}

The meta-analyses generally did not describe how the terms used in the database searches were generated. One of the meta-analyses explicitly mentioned that some search terms came from a controlled vocabulary. Another stated that they used the search terms provided by another study rather than attempting to generate the terms themselves. For the remaining articles, I could not directly determine from the text whether a controlled vocabulary was consulted.

It is possible that the authors used controlled vocabularies and chose not to describe this step. Robbins et al. (2004, p. 283), for example, hint at the use of different controlled vocabularies in different databases when they write, "Terminology searched for varied slightly for PsycINFO and Educational Resources Information Center on the basis of different terminology used in the theoretical models for psychological and educational literature."

To investigate controlled vocabulary use, I compared the search terms used in the metaanalyses to those provided by the relevant controlled vocabularies. Twenty-four of the metaanalyses provided complete lists of the search terms that they used. Of these, twenty-three metaanalyses indicated searching at least one database with a controlled vocabulary. I compared the 
terms listed by the authors to those listed in controlled vocabularies of the databases the authors searched. This comparison was limited to four controlled vocabularies: Thesaurus of Psychological Index Terms for searches in PsycINFO, PsycLIT, Psychological Abstracts or Psychological Literature; ERIC Thesaurus for searches in Education Resources Information Center (ERIC), Medical Subject Headings (MeSH) for searches in Medline or PubMed, and the CINAHL Subject Heading List for searches in the Cumulative Index to Nursing and Allied Health Literature (CINAHL). Search terms that were provided by the controlled vocabularies but not included in the meta-analysts' searches are listed in Table 2.

$<$ Table 2 here>

Additional search terms were uncovered from the controlled vocabularies for eighteen (78\%) of these twenty-three meta-analyses. Thirteen (57\%) of the twenty-three meta-analyses had additional terms in all of the relevant controlled vocabularies that I checked. Five (22\%) of these twenty-three searches included singular version of a term when the controlled vocabulary used the plural version. If interface used had included autostemming, or if the authors had used wildcard operators, these search terms would have been included. Only two (5\%) of all the meta-analyses mentioned that they used truncation or wildcard symbols in the search. For the others, if the authors of the meta-analyses used it, they did not document it.

Free-text searching relies on the searcher's ability to think of the relevant terms. It is difficult to assess how much the authors of the meta-analyses used free-text search strategies because it is difficult to establish exactly how many terms they missed. Nevertheless, some of the meta-analyses were notably limited in the breadth of terms included in the searches. One meta-analysis used the terms mentor, mentoring, protégé, mentorship, and career success to 
search for studies on the career benefits associated with mentoring. Within the abstract of this meta-analysis, career benefits, compensation, career satisfaction, and career outcomes all were used to describe the idea of career success, and the phrase career success was not used at all. Another meta-analysis combined the keywords smoking cessation, tobacco or nicotine or smoking, nicotine, and nicotine replacement therapy to find smoking cessation treatment outcome studies that used nicotine replacement therapy. Inspection of the citations in this metaanalysis revealed that transdermal nicotine, nicotine inhaler, nicotine chewing gum, nicotine gum, nicotine nasal spray, nicotine patch, and nicotine lozenge were other terms that could have been used to search for the concept of nicotine replacement therapy.

\section{Manual Searching}

Some form of manual searching was used in almost all, thirty-six (95\%), of the metaanalyses. Twenty-one (55\%) of the articles used backward citation searches in which they consulted the reference lists of the studies found for meta-analysis to find additional relevant studies. Seventeen (45\%) of the meta-analyses mentioned that the authors used the manual technique of consulting the reference lists of previous meta-analyses, review articles, or other articles. Another method used in twelve (32\%) meta-analyses was manually searching journals that publish in the field for relevant articles. In addition, one meta-analysis indicated that studies were found by manually searching the authors' personal files, and one meta-analysis indicated that studies were found through manual inspection of published articles without indicating how those articles were found. 


\section{Documenting the Search}

Ideally, a published research report should contain enough information for the technique to be reproducible by someone else. Within each of the search domains investigated: searching for unpublished studies, database searching, and manual searching, I examined whether this sort of detail was included in the reports of these meta-analyses (see Table 3). Missing information in any one area would make the search less than fully reproducible. Six (16\%) of the thirty-eight meta-analyses described all aspects of the search process in sufficient detail to be reproducible. Although many of the others provided detailed descriptions of most aspects of the search process, they did not provide complete descriptions of all aspects.

$<$ Table 3 here>

Six of the fifteen (40\%) meta-analyses that actively attempted to find unpublished studies documented this process enough to be reproducible. Of the meta-analysts that contacted other researchers either individually, via a listserv or through agencies, four out of ten (40\%) provided complete descriptions of these contacts either by naming them or describing how the names were located. Two (50\%) of the four meta-analyses that mentioned using conference proceedings or programs named all the proceedings, programs, or program databases used.

To be reproducible, a description of a database search would include the names of the databases searched, the date limits and a full list of search terms. Of the thirty-six meta-analyses that indicated database searching was used, eleven (31\%) provided complete descriptions of all three of these pieces of information. 
All thirty-six of the meta-analyses that involved a database search described the databases searched. These descriptions generally were clear, but there were some exceptions. For example, almost all (thirty-three) of the meta-analyses mentioned use of PsycINFO or PsycLIT to find studies, but two used alternate names: Psychological Abstracts International and Psychological Literature databases to refer to searches in what probably was PsycINFO or PsycLIT. One article named the search interface (WebSPIRS) rather than the databases within WebSPIRS that were searched.

Twenty-four (67\%) of these thirty-six articles included lists of all the search terms used, but three of these lists did not give enough information to reproduce the search. One metaanalysis provided a complete list, but it indicated that truncated keywords were used without indicating where the truncation began. The reader would not know if psychoimmunology was entered as psychoimmunolog* or psychoimmun*. Two others provided complete lists but were ambiguous about what database or databases were used with the terms. Twenty-one (58\%) provided a term list that could be used to reproduce the authors' search.

Of the thirty-six meta-analyses that indicated database searches were used, twenty-two $(61 \%)$ provided complete date ranges for all of the databases searched. Many of the others provided partial date ranges. These date ranges were incomplete because they indicated the beginning or end of the date range but not both, or they indicated the date ranges for just some of the databases searched.

To reproduce a manual search, the description would include the names and date ranges of all journals hand searched and the names of all review sources used to find references. Of the thirty-six meta-analyses that mentioned using any manual search techniques, nineteen (53\%) described them in a way that was fully reproducible. Of these, eleven (57\%) only manually 
searched the citations of studies found for the meta-analysis, and the other eight used other manual search methods.

Of the seventeen meta-analyses that used the reference lists of previous reviews, seven (41\%) indicated which reviews were used. The others gave partial lists of the review sources or indicated that this method was used without indicating the sources. Of the twelve meta-analyses that used manual searching of journals, most, eight (67\%), provided the names of all the journals that were searched, but only four (33\%) included the date range. Three (25\%) indicated both the names and the dates of all the journals that were manually searched.

\section{Discussion}

Overall, the results from this study show a mixed picture of the extent to which psychology meta-analysts applied different strategies to find studies and of their thoroughness in documenting the searches. Generally, the researchers used both manual searching and database searching to find studies. Generally, they searched more than one database. Sometimes the authors made an effort to find unpublished studies, and sometimes they did not. Generally, they did not provide enough documentation of all aspects of the search for it to be reproducible. At least based on their search descriptions, generally they did not use controlled vocabularies or wildcard operators in their searches of indexing and abstracting databases.

The results of this study do not quantify the effect that the limitations in these searches had on the results of the meta-analyses. The effect on the meta-analysis could be substantial if limitations in the search strategy resulted in missing a large number of studies with substantially different results from the included studies. On the other hand, if the studies that were not found 
had essentially the same results as the studies that were found, the results of a meta-analysis would be relatively unaffected by adding more search strategies or more terms to the database searches. Similarly, if only a small number of small studies would be found via additional search strategies, they would not produce much of a change in the results of the meta-analysis.

Extended search strategies even could have a deleterious effect on the results of a meta-analysis. Database searches for just one author, manually searching references from just one review article, and manually searching in just one journal could introduce biases if that search led to reports with one conclusion and ignored the authors, review articles and journals that would lead to reports with the opposite conclusion.

The results of this study also do not answer the question of why authors used some search strategies but not others. It is possible that the authors made conscious choices to limit their searches in a balance between the available resources and the goal of producing a high-quality meta-analysis. It also is possible that the authors were not aware of all the techniques available to increase the number of relevant studies they found.

Additional research on the effects of search limitations on the results of meta-analyses could help researchers and librarians make informed decisions about which strategies to include and which strategies to forgo. Ideally, this research also would consider the costs of a particular strategy, so a researcher would have guidance to balance the benefit of uncovering additional studies against the resources needed to use a particular approach.

The idea of balancing the benefits of an additional search strategy against the costs of doing so assumes, of course, that the researcher is aware that a strategy exists. It is unclear from the current study if the researchers were aware of the controlled vocabularies and wildcard tools that they could have used in their database searches. Some authors may have chosen to exclude 
terms from a controlled vocabulary out of concern for the time needed to consult the thesaurus and filter through additional results or because they felt the controlled vocabulary terms suggested in Table 2 were not on-topic. I find it hard to believe that the authors of more than half of the articles that provided complete lists of their search terms made this choice.

The authors may not realize how much of the literature they missed. Blair and Maron (1985) vividly demonstrated this problem. When they introduced a full-text searchable database to a law office, the system typically retrieved $20 \%$ of the relevant documents. Subjectively, the lawyers felt that the system was retrieving close to $75 \%$ of the relevant documents, and they were surprised that the recall was so low.

Librarians who serve psychology researchers have a role to play in improving the quality of searches used for meta-analyses. Weller (2004) has argued that the role of librarians in the meta-analysis process is essential. Librarians can help researchers understand the challenges of a thorough search and help them to make informed decisions about what databases to use, what search strategies to apply, and how to conduct efficient searches. This role could be an instructional one to aid the researchers devising their search strategies (e.g. Wykoff 1985). The role could also be as an active member of the research team (e.g. McGowan and Sampson 2005), or it could be an intermediate role of providing the database search and of assisting in document retrieval (e.g. Mead and Richards 1995).

Regardless of the approach, these roles fit squarely in the definition of what user services librarians do. As described in the Occupational Outlook Handbook (U.S. Department of Labor Bureau of Labor Statistics, 2004), “The job involves analyzing users' needs to determine what information is appropriate, as well as searching for, acquiring, and providing the information. The job also includes an instructional role, such as showing users how to access information." 
For librarians to successfully play this role in meta-analyses, they should understand the need for a high-recall, unbiased search in this situation and consider the tradeoffs involved in using or excluding different search strategies. Librarians also should discuss with the researchers the level of assistance that they are able to provide. Most importantly, the researchers and the librarians first must make contact with each other. With this contact, the librarian's expertise in searching can combine with the researcher's expertise in the subject area to produce a result better than either could produce alone. 


\section{References}

Meta-analyses considered for this report are marked with an asterisk.

* Allen, Tammy D., Lillian T. Eby, Mark L. Poteet, Elizabeth Lentz, and Lizzette Lima. 2004. Career benefits associated with mentoring for protégés: A meta-analysis. Journal of Applied Psychology 89 (1): 127-136. doi:10.1037/0021-9010.89.1.127

* Archer, John. 2004. Sex differences in aggression in real-world settings: A meta-analytic review. Review of General Psychology 8 (4): 291-322. doi:10.1037/1089-2680.8.4.291

Avenell, Alison, Helen H.G. Handoll, and Adrian M. Grant. 2001. Lessons for search strategies from a systematic review, in The Cochrane Library, of nutritional supplementation trials in patients after hip fracture. American Journal of Clinical Nutrition 73 (3): 505-10. http://www.ajcn.org/cgi/reprint/73/3/505.

Bates, Marcia J. 1984. The fallacy of the perfect thirty-item online search. $R Q 24: 43-50$. 1988. How to use controlled vocabularies more effectively in online searching. Online 12: 45-56.

1989. The design of browsing and berrypicking techniques for the online search interface. Online Review 13: 407-424.

Begg, Colin B. and Jesse A. Berlin. 1988. Publication bias: A problem in interpreting medical data. Journal of the Royal Statistical Society. Series A (Statistics in Society) 151 (3): 419-463. http://links.jstor.org/sici?sici=0964- 
1998\%281988\%29151\%3A3\%3C419\%3APBAPII\%3E2.0.CO\%3B2-E.

Bennett, Derrick A., Nancy K. Latham, Carolyn Stretton, and Craig S. Anderson. 2004. Capturerecapture is a potentially useful method for assessing publication bias. Journal of Clinical Epidemiology 57 (4): 349-357. doi:10.1016/j.jclinepi.2003.09.015

Bent, Stephen, Kaveh G. Shojania, and Sanjay Saint. 2004. The use of systematic reviews and meta-analyses in infection control and hospital epidemiology. American Journal of Infection Control 32 (4): 246-254. doi:10.1016/j.ajic.2003.10.004

Blair, David C. and M.E. Maron. 1985. An evaluation of retrieval effectiveness for a full-text document-retrieval system. Communications of the ACM 28 (3): 289-299. doi: $10.1145 / 3166.3197$

* Bogg, Tim and Brent W. Roberts. 2004. Conscientiousness and health-related behaviors: A meta-analysis of the leading behavioral contributors to mortality. Psychological Bulletin 130 (6): 887-919. doi:10.1037/0033-2909.130.6.887

* Bono, Joyce E. and Timothy A. Judge. 2004. Personality and transformational and transactional leadership: A meta-analysis. Journal of Applied Psychology 89 (5): 901910. doi:10.1037/0021-9010.89.5.901

Brettle, Alison J. and Andrew F. Long. 2001. Comparison of bibliographic databases for information on the rehabilitation of people with severe mental illness. Bulletin of the Medical Library Association 89 (4): 353-362. http://www.pubmedcentral.gov/picrender.fcgi?artid=57964\&blobtype=pdf. 
* Cepeda-Benito, Antonio, Jose T. Reynoso, and Stephen Erath. 2004. Meta-analysis of the efficacy of nicotine replacement therapy for smoking cessation: Differences between men and women. Journal of Consulting and Clinical Psychology 77 (4): 712-722. doi:10.1037/0022-006X.72.4.712

* Cohn, Lawrence D. and P. Michiel Westenberg. 2004. Intelligence and maturity: Meta-analytic evidence for the incremental and discriminant validity of Loevinger's Measure of Ego Development. Journal of Personality and Social Psychology 86 (5): 760-772. doi:10.1037/0022-3514.86.5.760

* Curtis, Nicola M., Kevin R. Ronan, and Charles M. Borduin. 2004. Multisystemic Treatment: A meta-analysis of outcome studies. Journal of Family Psychology 18 (3): 411-419.

Dickersin, K., R. Scherer, and C. Lefebvre. 1994. Systematic reviews: Identifying relevant studies for systematic reviews. BMJ 309 (6964): 1286-1291. http://bmj.bmjjournals.com/cgi/content/full/309/6964/1286.

* Dickerson, Sally S. and Margaret E. Kemeny. 2004. Acute stressors and cortisol responses: A theoretical integration and synthesis of laboratory research. Psychological Bulletin 130 (3): 355-391. doi:10.1037/0033-2909.130.3.355

* DiMatteo, M. Robin. 2004. Social support and patient adherence to medical treatment: A metaanalysis. Health Psychology 23 (2): 207-218. doi:10.1037/0278-6133.23.2.207

Egger, Matthias, Tanja Zellweger-Zähner, Martin Schneider, Christoph Junker, Christian Lengeler, and Gerd Antes. 1997. Language bias in randomised controlled trials published 
in English and German. The Lancet 350 (9074): 326-329. doi:10.1016/S01406736(97)02419-7

* Frazier, Thomas W., Heath A. Demaree, and Eric A. Youngstrom. 2004. Meta-analysis of intellectual and neuropsychological test performance in attention-deficit/hyperactivity disorder. Neuropsychology 18 (3): 543-555. doi:10.1037/0894-4105.18.3.543

* Gregory, Robert J., Sally Schwer Canning, Tracy W. Lee, and Joan C. Wise. 2004. Cognitive bibliotherapy for depression: A meta-analysis. Professional Psychology: Research and Practice 35 (3): 275-280. doi:10.1037/0735-7028.35.3.275

Grégoire, Geneviève, François Derderian, and Jacques Le Lorier. 1995. Selecting the language of the publications included in a meta-analysis: Is there a Tower of Babel bias? Journal of Clinical Epidemiology 48 (1): 159-163. doi:10.1016/0895-4356(94)00098-B

Hawkins, Donald T. and Robert Wagers. 1982. Online bibliographic search strategy development. Online 6 (3): 12-19.

* Heller, Daniel, David Watson, and Remus Ilies. 2004. The role of person versus situation in life satisfaction: A critical examination. Psychological Bulletin 130 (4): 574-600. doi:10.1037/0033-2909.130.4.574

* Henry, Julie D. and John R. Crawford. 2004a. A meta-analytic review of verbal fluency performance following focal cortical lesions. Neuropsychology 18 (2): 284-295. doi:10.1037/0894-4105.18.2.284

* ___ 2004b. A meta-analytic review of verbal fluency performance in patients with traumatic 
brain injury. Neuropsychology 18 (4): 621-628. doi:10.1037/0894-4105.18.4.621

* Henry, Julie D., Mairi S. MacLeod, Louise H. Phillips, and John R. Crawford. 2004. A metaanalytic review of prospective memory and aging. Psychology and Aging 19 (1): 27-39. doi:10.1037/0882-7974.19.1.27

* Hervey, Aaron S., Jeffery N. Epstein, and John F. Curry. 2004. Neuropsychology of adults with attention-deficit/hyperactivity disorder: A meta-analytic review. Neuropsychology 18 (3): 485-503. doi:10.1037/0894-4105.18.3.485

Hood, William W. and Concepción S. Wilson. 2001. The scatter of documents over databases in different subject domains: How many databases are needed? Journal of the American Society for Information Science and Technology 52 (14): 1242-1254. doi:10.1002/asi.1191

* Hoyer, William J., Robert S. Stawski, Christina Wasylyshyn, and Paul Verhaeghen. 2004. Adult age and digit symbol substitution performance: A meta-analysis. Psychology and Aging 19 (1): 211-214. doi:10.1037/0882-7974.19.1.211

* Jetten, Jolanda, Russell Spears, and Tom Postmes. 2004. Intergroup distinctiveness and differentiation: A meta-analytic integration. Journal of Personality and Social Psychology 86 (6): 862-879. doi:10.1037/0022-3514.86.6.862

* Judge, Timothy A. and Daniel M. Cable. 2004. The effect of physical height on workplace success and income: Preliminary test of a theoretical model. Journal of Applied Psychology 89 (3): 428-441. doi:10.1037/0021-9010.89.3.428 
* Judge, Timothy A., Amy E. Colbert, and Remus Ilies. 2004. Intelligence and leadership: A quantitative review and test of theoretical propositions. Journal of Applied Psychology 89 (3): 542-552. doi:10.1037/0021-9010.89.3.542

* Judge, Timothy A. and Ronald F. Piccolo. 2004. Tranformational and transactional leadership: A meta-analytic test of their relative validity. Journal of Applied Psychology 89 (5): 755768. doi:10.1037/0893-3200.18.3.411

* Judge, Timothy A., Ronald F. Piccolo, and Remus Ilies. 2004. The forgotten ones? The validity of consideration and initiating structure in leadership research. Journal of Applied Psychology 89 (1): 36-51. doi:10.1037/0021-9010.89.1.36

* Kulic, Kevin R., Arthur M. Horne, and John C. Dagley. 2004. A comprehensive review of prevention groups for children and adolescents. Group Dynamics: Theory, Research, and Practice 8 (2): 139-151. doi:10.1037/1089-2699.8.2.139

* Kumkale, G. Tarcan and Dolores Albarracín. 2004. The sleeper effect in persuasion: A metaanalytic review. Psychological Bulletin 130 (1): 143-172. doi:10.1037/00332909.130.1.143

* Kuncel, Nathan R., Sarah A. Hezlett, and Deniz S. Ones. 2004. Academic performance, career potential, creativity, and job performance: Can one construct predict them all? Journal of Personality and Social Psychology 86 (1): 148-161. doi:10.1037/0022-3514.86.1.148

* Lackner, Jeffrey M., Stephen Morley, Clare Dowzer, Christina Mesmer, and Simon Hamilton. 2004. Psychological treatments for irritable bowel syndrome: A systematic review and 
meta-analysis. Journal of Consulting and Clinical Psychology 72 (6): 1100-1113. doi:10.1037/0022-006X.72.6.1100

Lancaster, Frederick Wilfrid. 1972. Vocabulary Control for Information Retrieval. Washington, D.C.: Information Resources Press.

* Leaper, Campbell and Tara E. Smith. 2004. A meta-analytic review of gender variations in children's language use: Talkativeness, affiliative speech, and assertive speech. Developmental Psychology 40 (6): 993-1027. doi:10.1037/0012-1649.40.6.993

* Lorber, Michael F. 2004. Psychophysiology of aggression, psychopathy, and conduct problems: A meta-analysis. Psychological Bulletin 130 (4): 531-552. doi:10.1037/00332909.130.4.531

* Martire, Lynn M., Amy P. Lustig, Richard Schulz, Gregory E. Miller, and Vicki S. Helgeson. 2004. Is it beneficial to involve a family member? A meta-analysis of psychosocial interventions for chronic illness. Health Psychology 23 (6): 599-611. doi:10.1037/02786133.23.6.599

McAuley, Laura, Ba' Pham, Peter Tugwell, and David Moher. 2000. Does the inclusion of grey literature influence estimates of intervention effectiveness reported in meta-analyses? The Lancet 356 (9237): 1228-1231. doi:10.1016/S0140-6736(00)02786-0

McGowan, Jessie and Margaret Sampson. 2005. Systematic reviews need systematic searchers. Journal of the Medical Library Association 93 (1): 74-80. http://www.pubmedcentral.gov/picrender.fcgi?artid=545125\&blobtype=pdf. 
McLeod, Bryce D. and John R. Weisz. 2004. Using dissertations to examine potential bias in child and adolescent clinical trials. Journal of Consulting and Clinical Psychology 72 (2): 235-251. doi:10.1037/0022-006X.72.2.235

Mead, Thomas L. and Daniel T. Richards. 1995. Librarian participation in meta-analysis projects. Bulletin of the Medical Library Association 83 (4): 461-464. http://www.pubmedcentral.nih.gov/picrender.fcgi?artid=226065\&blobtype=pdf.

* Mezulis, Amy H., Lyn Y. Abramson, Janet S. Hyde, and Benjamin L. Hankin. 2004. Is there a universal positivity bias in attributions? A meta-analytic review of individual, developmental, and cultural differences in the self-serving attributional bias. Psychological Bulletin 130 (5): 711-747. doi:10.1037/0033-2909.130.5.711

Miner, John B. and Nambury S. Raju. 2004. Risk propensity differences between managers and entrepreneurs and between low- and high-growth entrepreneurs: A reply in a more conservative vein. Journal of Applied Psychology 89 (1): 3-13. doi:10.1037/00219010.89 .1 .3

Moher, David, Deborah Cook, Susan Eastwood, Ingram Olkin, Drummond Rennie, and Donna F. Stroup. 1999. Improving the quality of reports of meta-analyses of randomised controlled trials: the QUOROM Statement. The Lancet 354 (9193): 1896-1900. doi:10.1016/S0140-6736(99)04149-5

* Moyer, Christopher A., James Rounds, and James W. Hannum. 2004. A meta-analysis of massage therapy research. Psychological Bulletin 130 (1): 3-18. doi:10.1037/00332909.130.1.3 
* Nummenmaa, Lauri and Pekka Niemi. 2004. Inducing affective states with success-failure manipulations: A meta-analysis. Emotion 4 (2): 207-214. doi:10.1037/1528-3542.4.2.207

Patrick, Timothy B., George Demiris, Lillian C. Folk, David E. Moxley, Joyce A. Mitchell and Donghua Tao. 2004. Evidence-based retrieval in evidence-based medicine. Journal of the Medical Library Association 92 (2): 196-199. http://www.pubmedcentral.gov/picrender.fcgi?artid=385300\&blobtype=pdf.

* Prochaska, Judith J., Kevin Delucchi, and Sharon M. Hall. 2004. A meta-analysis of smoking cessation interventions with individuals in substance abuse treatment or recovery. Journal of Consulting and Clinical Psychology 72 (6): 1144-1156. doi:10.1037/0022006X.72.6.1144

* Reger, Mark A., Robert K. Welsh, G. Stennis Watson, Brenna Cholerton, Laura D. Baker, and Suzanne Craft. 2004. The relationship between neuropsychological functioning and driving ability in dementia: A meta-analysis. Neuropsychology 18 (1): 85-93. doi:10.1037/0894-4105.18.1.85.

* Rhodes, Matthew G. 2004. Age-related differences in performance on the Wisconsin Card Sorting Test: A meta-analytic review. Psychology and Aging 19 (3): 482-494. doi:10.1037/0882-7974.19.3.482

* Robbins, Steven B., Kristy Lauver, Huy Le, Daniel Davis, Ronelle Langley, and Aaron Carlstrom. 2004. Do psychosocial and study skill factors predict college outcomes? A meta-analysis. Psychological Bulletin 130 (2): 261-288. doi:10.1037/00332909.130.2.261 
* Rotello, Caren M., Neil A. Macmillan, and John A. Reeder. 2004. Sum-difference theory of remembering and knowing: A two-dimensional signal-detection model. Psychological Review 111 (3): 588-616. doi:10.1037/0033-295X.111.3.588

Sampson, Margaret, Nicholas J. Barrowman, David Moher, Terry P. Klassen, Ba' Pham, Robert Platt, Philip D. St. John, Raymond Viola, and Parminder Raina. 2003. Should metaanalysts search Embase in addition to Medline? Journal of Clinical Epidemiology 56 (10): 943-955. doi:10.1016/S0895-4356(03)00110-0

Savoy, Jacques. 2005. Bibliographic database access using free-text and controlled vocabulary: An evaluation. Information Processing and Management 41 (4): 873-890. doi:10.1016/j.ipm.2004.01.004

Schell, Cathrina L. and Richard J. Rathe. 1992. Meta-analysis: a tool for medical and scientific discoveries. Bulletin of the Medical Library Association 80 (3): 219-222. http://www.pubmedcentral.nih.gov/picrender.fcgi?artid=225660\&blobtype=pdf.

* Segerstrom, Suzanne C. and Gregory E. Miller. 2004. Psychological stress and the human immune system: A meta-analytic study of 30 years of inquiry. Psychological Bulletin 130 (4): 601-630. doi:10.1037/0033-2909.130.4.601

* Small, Brent J., Christopher B. Rosnick, Laura Fratiglioni, and Lars Bäckman. 2004. Apolipoprotein E and cognitive performance: A meta-analysis. Psychology and Aging 19 (4): 592-600. doi:10.1037/0882-7974.19.4.592

Stewart, Wayne H. Jr. and Philip L. Roth. 2001. Risk propensity differences between 
entrepreneurs and managers: A meta-analytic review. Journal of Applied Psychology 86 (1): 145-153. doi:10.1037/0021-9010.86.1.145

2004. Data quality affects meta-analytic conclusions: A response to Miner and Raju (2004) concerning entrepreneurial risk propensity. Journal of Applied Psychology 89 (1): 14-21. doi:10.1037/0021-9010.89.1.14

* Stice, Eric and Heather Shaw. 2004. Eating disorder prevention programs: A meta-analytic review. Psychological Bulletin 130 (2): 206-227. doi:10.1037/0033-2909.130.2.206

Tenopir, Carol. 1987. Searching by controlled vocabulary or free text? Library Journal 112 (19): 58-59. http://search.epnet.com/login.aspx ?direct=true \&db=aph\&an=7556260.

U.S. Department of Labor Bureau of Labor Statistics. 2004. Librarians. Occupational Outlook Handbook. http://www.bls.gov/oco/ocos068.htm.

van der Weijden, Trudy, C. Joris IJzermans, Geert-Jan Dinant, Nico P. van Duijn, Riekie de Vet, and Frank Buntinx. 1997. Identifying relevant diagnostic studies in Medline. The diagnostic value of the erythrocyte sedimentation rate (ESR) and dipstick as an example. Family Practice 14 (3): 204-208. http://fampra.oxfordjournals.org/cgi/reprint/14/3/204.

* van Dick, Rolf, Ulrich Wagner, Thomas F. Pettigrew, Oliver Christ, Carina Wolf, Thomas Petzel, Vanessa Smith Castro, and James S. Jackson. 2004. Role of perceived importance in intergroup contact. Journal of Personality and Social Psychology 87 (2): 211-227. doi:10.1037/0022-3514.87.2.211

Walker, Alvin Jr. and Sarah N. Mulholland. 1992. The Thesaurus of Psychological Index Terms: 
A historical review. Behavioral \& Social Sciences Librarian 11 (2): 39-57.

Weller, Ann C. 2004. Mounting evidence that librarians are essential for comprehensive literature searches for meta-analyses and Cochrane reports. Journal of the Medical Library Association 92 (2): 163-164.

http://www.pubmedcentral.gov/picrender.fcgi?artid=385293\&blobtype=pdf.

Wykoff, Leslie W. 1985. Meta-analysis and its implications for search intermediaries. Medical Reference Services Quarterly 4 (4): 71-75. 
Table 1 Search methods described in psychology meta-analyses Search Methods Described in Meta-Analysis Number

of meta-

analyses

\begin{tabular}{lrr}
\hline Searching for unpublished studies & 15 & 39 \\
Dissertation search & 11 & 29 \\
Contacting relevant researchers or organizations & 10 & 26 \\
Conference proceedings & 4 & 11 \\
\hline Database Searching & 36 & 95 \\
More than one database & 30 & 79 \\
Truncation or wildcard operators & 2 & 5 \\
Controlled vocabulary & 1 & 3 \\
\hline Manual Searching & 36 & 95 \\
Reference lists of studies included in meta-analysis & 21 & 55 \\
Reference lists of other articles & 17 & 45 \\
Journal scanning & 12 & 32 \\
\hline Other methods & & \\
Author searching & 3 & 8 \\
Forward citation searching & 2 & 5 \\
\hline
\end{tabular}

Find studies to include in meta-analyses

pg. 36 of 40 
Table 2 Additional search terms found by consulting controlled vocabularies

\begin{tabular}{|c|c|c|}
\hline Article $^{1}$ & $\begin{array}{c}\text { Databases } \\
\text { used }\end{array}$ & Controlled vocabulary terms NOT searched $^{2}$ \\
\hline $\begin{array}{l}\text { Allen et al.--Career Benefits Associated With } \\
\text { Mentoring for Protégés: A Meta-Analysis. }\end{array}$ & PsyclNFO & occupational success \\
\hline $\begin{array}{l}\text { Archer--Sex Differences in Aggression in Real- } \\
\text { World Settings: A Meta-Analytic Review. }\end{array}$ & $\begin{array}{l}\text { PsycINFO, } \\
\text { PsycLIT }\end{array}$ & aggressiveness \\
\hline \multirow[t]{2}{*}{$\begin{array}{l}\text { Bogg and Roberts--Conscientiousness and Health- } \\
\text { Related Behaviors: A Meta-Analysis of the Leading } \\
\text { Behavioral Contributors to Mortality. }\end{array}$} & PsycINFO & $\begin{array}{l}\text { impulsiveness, Sixteen Personality Factors } \\
\text { Questionnaire, dietary restraint, psychosexual } \\
\text { behavior, sexual risk taking, marijuana usage }\end{array}$ \\
\hline & PubMed & $\begin{array}{l}\text { Cattell Personality Factor Questionnaire, MMPI, } \\
\text { sexual behavior, substance-related disorders }\end{array}$ \\
\hline $\begin{array}{l}\text { Bono and Judge--Personality and Transformational } \\
\text { and Transactional Leadership: A Meta-Analysis. }\end{array}$ & PsyclNFO & --- \\
\hline \multirow{2}{*}{$\begin{array}{l}\text { Cepeda-Benito, Reynoso and Erath, Stephen--Meta- } \\
\text { Analysis of the Efficacy of Nicotine Replacement } \\
\text { Therapy for Smoking Cessation: Differences } \\
\text { Between Men and Women. }\end{array}$} & Medline & --- \\
\hline & $\begin{array}{l}\text { Psychological } \\
\text { Abstracts }\end{array}$ & --- \\
\hline \multirow[t]{2}{*}{$\begin{array}{l}\text { Curtis, Ronan and Borduin--Multisystemic } \\
\text { Treatment: A Meta-Analysis of Outcome Studies. }\end{array}$} & $\begin{array}{l}\text { Psychological } \\
\text { Literature }\end{array}$ & --- \\
\hline & ERIC & $\begin{array}{l}\text { delinquency, delinquent rehabilitation, family } \\
\text { relationship, parent child relationship }\end{array}$ \\
\hline \multirow{2}{*}{$\begin{array}{l}\text { Dickerson and Kemeny--Acute Stressors and } \\
\text { Cortisol Responses: A Theoretical Integration and } \\
\text { Synthesis of Laboratory Research. }\end{array}$} & Medline & neurosecretory systems \\
\hline & PsyclNFO & Hypothalamo Pituitary Adrenal System \\
\hline \multirow{2}{*}{$\begin{array}{l}\text { DiMatteo--Social Support and Patient Adherence to } \\
\text { Medical Treatment: A Meta-Analysis. }\end{array}$} & Medline & treatment refusal, patient dropouts \\
\hline & PsycLIT & $\begin{array}{l}\text { treatment compliance, treatment refusal, treatment } \\
\text { dropouts }\end{array}$ \\
\hline \multirow{2}{*}{$\begin{array}{l}\text { Frazier, Demaree and Youngstrom--Meta-Analysis } \\
\text { of Intellectual and Neuropsychological Test } \\
\text { Performance in Attention-Deficit/Hyperactivity } \\
\text { Disorder. }\end{array}$} & Medline & intelligence tests \\
\hline & PsyclNFO & intelligence quotient, cognitive ability \\
\hline $\begin{array}{l}\text { Henry and Crawford (2004a)--A Meta-Analytic } \\
\text { Review of Verbal Fluency Performance Following }\end{array}$ & PsycLIT & --- \\
\hline
\end{tabular}

Find studies to include in meta-analyses

pg. 37 of 40 


\begin{tabular}{|c|c|c|}
\hline Article $^{1}$ & $\begin{array}{c}\text { Databases } \\
\text { used }\end{array}$ & Controlled vocabulary terms NOT searched $^{2}$ \\
\hline \multicolumn{3}{|l|}{ Focal Cortical Lesions. } \\
\hline $\begin{array}{l}\text { Henry and Crawford (2004b)--A Meta-Analytic } \\
\text { Review of Verbal Fluency Performance in Patients } \\
\text { With Traumatic Brain Injury. }\end{array}$ & PsycLIT & --- \\
\hline $\begin{array}{l}\text { Henry et al.--A Meta-Analytic Review of Prospective } \\
\text { Memory and Aging. }\end{array}$ & PsycLIT & intention \\
\hline \multirow{2}{*}{$\begin{array}{l}\text { Hervey, Epstein and Curry--Neuropsychology of } \\
\text { Adults With Attention-Deficit/Hyperactivity Disorder: } \\
\text { A Meta-Analytic Review. }\end{array}$} & Medline & neuropsychological tests \\
\hline & PsycINFO & hyperkinesis, neuropsychological assessment \\
\hline \multirow{2}{*}{$\begin{array}{l}\text { Kumkale, and Albarracín--The Sleeper Effect in } \\
\text { Persuasion: A Meta-Analytic Review. }\end{array}$} & ERIC & persuasive discourse, attitudes, opinions, beliefs \\
\hline & PsycINFO & persuasive communication, attitudes \\
\hline \multirow{2}{*}{$\begin{array}{l}\text { Lorber--Psychophysiology of Aggression, } \\
\text { Psychopathy, and Conduct Problems: A Meta- } \\
\text { Analysis. }\end{array}$} & Medline & --- \\
\hline & PsycINFO & $\begin{array}{l}\text { cardiovascular reactivity, skin resistance, physiological } \\
\text { correlates }\end{array}$ \\
\hline \multirow{4}{*}{$\begin{array}{l}\text { Martire et al.--Is It Beneficial to Involve a Family } \\
\text { Member? A Meta-Analysis of Psychosocial } \\
\text { Interventions for Chronic Illness. }\end{array}$} & CINAHL & $\begin{array}{l}\text { patients, chronic disease, caregivers, spouses, } \\
\text { significant other }\end{array}$ \\
\hline & ERIC & patients, caregivers, spouses \\
\hline & $\begin{array}{l}\text { Medline, } \\
\text { PubMed }\end{array}$ & chronic disease, caregivers, spouses \\
\hline & PsycINFO & $\begin{array}{l}\text { patients, caregivers, spouses, husbands, wives, } \\
\text { significant others }\end{array}$ \\
\hline \multirow{2}{*}{$\begin{array}{l}\text { Mezulis et al.--Is There a Universal Positivity Bias in } \\
\text { Attributions? A Meta-Analytic Review of Individual, } \\
\text { Developmental, and Cultural Differences in the Self- } \\
\text { Serving Attributional Bias. }\end{array}$} & ERIC & --- \\
\hline & PsycINFO & self perception, social perception \\
\hline \multirow{3}{*}{$\begin{array}{l}\text { Moyer, Rounds and Hannum--A Meta-Analysis of } \\
\text { Massage Therapy Research. }\end{array}$} & CINAHL & manual therapy, myofascial release \\
\hline & Medline & kinesiology applied \\
\hline & PsycINFO & --- \\
\hline \multirow{2}{*}{$\begin{array}{l}\text { Nummenmaa and Niemi--Inducing Affective States } \\
\text { With Success-Failure Manipulations: A Meta- } \\
\text { Analysis. }\end{array}$} & ERIC & moods, emotional response \\
\hline & PsycINFO & $\begin{array}{l}\text { emotional responses, emotions, emotional states, } \\
\text { achievement }\end{array}$ \\
\hline Rhodes--Age-Related Differences in Performance & Medline & --- \\
\hline
\end{tabular}

Find studies to include in meta-analyses

pg. 38 of 40 


\begin{tabular}{|c|c|c|}
\hline Article $^{1}$ & $\begin{array}{c}\text { Databases } \\
\text { used }\end{array}$ & Controlled vocabulary terms NOT searched $^{2}$ \\
\hline $\begin{array}{l}\text { on the Wisconsin Card Sorting Test: A Meta-Analytic } \\
\text { Review. }\end{array}$ & PsyclNFO & --- \\
\hline \multirow{2}{*}{$\begin{array}{l}\text { Robbins et al.--Do Psychosocial and Study Skill } \\
\text { Factors Predict College Outcomes? A Meta- } \\
\text { Analysis. }\end{array}$} & ERIC & --- \\
\hline & PsycINFO & $\begin{array}{l}\text { college students }{ }^{3} \text {, creativity, expectations, educational } \\
\text { aspirations, occupational aspirations, family relations, } \\
\text { peer relations }\end{array}$ \\
\hline \multirow{2}{*}{$\begin{array}{l}\text { Segerstrom and Miller--Psychological Stress and the } \\
\text { Human Immune System: A Meta-Analytic Study of } \\
30 \text { Years of Inquiry. }\end{array}$} & Medline & life change events \\
\hline & PsyclNFO & $\begin{array}{l}\text { life experiences, immunology, immunoreactivity, } \\
\text { psychoneuroimmunology }\end{array}$ \\
\hline \multirow{3}{*}{$\begin{array}{l}\text { Stice and Shaw--Eating Disorder Prevention } \\
\text { Programs: A Meta-Analytic Review. }\end{array}$} & CINAHL & eating disorders, female athlete triad \\
\hline & Medline & eating disorders \\
\hline & PsyclNFO & eating disorders \\
\hline
\end{tabular}

${ }^{1}$ Complete references are provided in the reference section.

${ }^{2}$ Terms listed in italic are plurals of the terms used by the authors and would have been found if the authors used wildcard operators.

${ }^{3}$ This meta-analysis used "students" as a search term but not in the facet of the search related to higher education. Records containing "college students" also had to contain "higher education," "undergraduate study," "undergraduate students," or "college attendance" to be found with the authors' search strategy. 
Table 3 Detail provided in description of search strategy

\begin{tabular}{lrrr}
\hline Description Feature & $\begin{array}{r}\text { Number } \\
\text { possible }\end{array}$ & $\begin{array}{r}\text { Number } \\
\text { providing }\end{array}$ & $\%$ \\
\hline All aspects of search reproducible & 38 & 6 & 16 \\
\hline Complete description of search for unpublished studies & 15 & 6 & 40 \\
Names or reproducible description of contacts & 10 & 4 & 40 \\
Names of conference proceedings / database & 4 & 2 & 50 \\
\hline Complete description of database search & 36 & 11 & 31 \\
Names of databases searched & 36 & 35 & 97 \\
All search terms used & 36 & 24 & 67 \\
How and where all search terms used & 36 & 21 & 58 \\
Beginning and ending date limits & 36 & 22 & 61 \\
\hline Complete description of manual search & 36 & 19 & 53 \\
Names of all review sources used to find references & 17 & 7 & 41 \\
Complete date ranges of journals manually searched & 12 & 4 & 33 \\
Names of all journals manually searched & 12 & 8 & 67 \\
Names and date ranges of journals manually searched & 12 & 3 & 25 \\
\hline
\end{tabular}

Find studies to include in meta-analyses 